\title{
Construction of Smart learning Pattern Based On Micromessage and Identity Path Analysis
}

\author{
Zhi-Hui JIANG \\ Department of Electronic and Information Engineering \\ Changsha Normal University \\ Hunan, Changsha, 410100, China \\ 68001110@qq.com
}

\author{
Zhi-Cheng NIE \\ Instruction Quality Management Office \\ Hunan University of Science and Engineering \\ Hunan, Changsha, 410100, China \\ 642687850@qq.com
}

\begin{abstract}
Smart learning is one of the hot issues in the field of study and research of Educational Technology. Micromessage, as a kind of instant messaging tool, could well provide the corresponding learning platform for smart learning. This paper, on the basis of micromessage, proposes the construction of smart learning pattern and identity path analysis, expect to promote learners to efficiently study in smart learning environment.
\end{abstract}

Keywords-micromessage; smart learning; learning pattern; identity path

\section{INTRODUCTION}

As the 4G network increase in coverage, Wi-Fi and smartphone prices decline, mobile Internet penetration is continuing the blow-out trend. According to China Internet Development Condition Statistics Report, up to the end of December, 2013, our country handset web cam scale had reached 500,000,000, in which students were one of the main communities, occupies $26.8 \%$. In our country's universities, students visit the Internet through the smart phone popularly [1] The daily activities of college students are given priority with learning, and mobile learning is getting more and more favor of students because of the characteristics of being convenient and quick. Many college students have begun to search, download and use the applications of mobile phone autonomously, such as memorizing words. College students' demand for mobile learning more and more strong. American education technology planning draft was released as early as 2010. The Transformation Education In The United States: Technology To Promote Learning put forward that the new emerging technologies for learners' help is not only limited to the traditional knowledge, but helps them get the necessary comprehensive ability in twenty-first Century, including the decision thinking, complex problem solving, collaboration, multimedia communication ability, etc. ${ }^{[2]}$ And the way of learning must also adapt to the demand of smart environment, and generate a change in order to achieve the composite learning objectives.

WeChat is a social communication platform for the integration of mobile software. As a kind of software which focuses on mobile terminal function, WeChat can offer a new platform and application innovation space for smart learning. WeChat has a high degree of utilization and adhesion for its real-time communication and good experience among students group. Multiple interactive modes make information more flexible and diverse, and a new type of platform support makes smart learning application exploitation more

This study was supported by: 1. Education research base project for educational information technology of Hunan province (project no.:

[2012]32); 2. Special research project for education science of the 12th FiveYear Plan in Hunan province (project no.: XJK014BJD014). Zhi-Cheng NIE is the corresponding author. convenient and efficient. Many scholars have been concerned about the WeChat application education and have carried on positive explorations, mainly including the design and implementation of hybrid learning based on WeChat support [3], the WeChat public platform application in the field of education in colleges and universities by discussing the possibility and reality ${ }^{[4]}$, WeChat application practice in the field of education and training, etc. Some scholars also analyze the main functions and the design principles of WeChat mobile learning support from the theoretical level [5]. WeChat provides more choices and more rich communication ways for mobile learners, but there are still limitations regarding intelligent terminals popularization, poor resources and wireless network cost ${ }^{[6]}$. Existing research analyzed and found that WeChat could effectively promote the development of mobile learning from the aspects of theory and practice, but overall it is still in the exploratory stage. Systematic research on the WeChat application in the educational field has yet to be spread from information, learning support, platform building and so on. In this paper, in order to construct a new, lightweight, personalized learning space and platform for the development of WeChat class social software, we study the construction of the smart learning model and the identity path.

\section{DEFINITON OF SMART LEARNING}

The key of keeping up with the times for educational reform is to speed up the transformation of the mode of education and the way of learning. Now the world is developing smart education actively, and smart learning is the cornerstone of smart education. It is an inevitable trend of the transformation of learning style in the tide of smart education. It is the important direction of transformation for ability concept, knowledge concept and learning concept under the drive of NGIT, such as Internet of Things, Cloud Computing, Big Data, Ubiquitous Network, etc ${ }^{[7]}$. There have been some domestic and foreign scholars discussing about the connotation of smart learning. Gyu-seong Rho ${ }^{[8]}$ thinks that smart learning is a self-directed learning (SDL) and peopleoriented way of learning. It is easy to access to the information resources through the integration of information technology and learning activities to support the effective interaction between learners or between learners and teachers. At the same time it also needs to design the self-directed learning environment. Zhu Zhiting [9] argues that smart learning is to use appropriate technology actively and flexibly to promote learners' meaning construction, win-win cooperation and innovative practice, and to constantly improve, purify and 
adapt environment. He $\mathrm{Bin}^{[\mathbf{1 0 ]}}$ argue that smart learning is a new learning paradigm, which is self-directed learning (SDL), learner-centered and has a complete learning experience. We hold that smart learning is a learning process in which learners can acquire learning resources according to the requirement, it is flexible and easy to carry out learning activities, and construct knowledge network and interpersonal network rapidly. The ultimate goal of smart learning is to develop the learner's wisdom and improve the learner's innovation ability, fully reflecting the personal, natural, sustainable, efficient and immersed way of learning.

\section{ANALYSIS OF THE FEATURE OF SMART LEARNING BASED ON WECHAT PLATFORM}

WeChat is a mobile software created and put into market by Tencent on January 21, 2011, which can make people send voice message, video, pictures and text on Internet quickly, chat with group, and make voice input and reminder. Up to the third quarter of 2013, the number of active users monthly of WeChat have reached 271.9 million.As a social software, WeChat makes it possible for human-computer interaction, human-human interaction, human-environment interaction in smart learning, and provide online and offline services and the necessary context for learners. areas:

Its main features can be summed up in the following

\section{A. It Can Achieve a Variety Of Ways Of Learning Effectively}

With the maturation of social software technologies, WeChat has become the main platform for the mobile learning based on the analysis of learner characteristics, namely WeChat + APP learning platform. Based on this platform, the online functions (preparation, study, review, answer, analysis and communication of knowledge) and the offline functions (discussion, interaction, communication) of mobile learning can be achieved. It can not only provide a possible way to achieve the flipped classroom learning, but also achieve the features such as the query of results, evaluation, performance assessment and monitoring of the learning process, etc.

\section{B. It Offers a Variety Of Learning Resources on the WeChat Learning Platform}

Learners manage and publish educational institutions information through effective account management, permissions control and independent APP. The dissemination of the contents of WeChat embodied in the form of combination of graphics, text, audio and video. It can be applied in various forms through different combinations of content distribution and it is easy to be chosen. Chunks and content can be designed in accordance with the knowledge content and the length of learning time, and learning resources can be cut into small chunks or single learning topics reasonably according to the needs of learners, so that students can accept, absorb, digest step by step. It provides the foundation for learning miniaturization design and stimulates learner motivation effectively.

\section{Instant Interaction}

WeChat provides some related services such as account system, two-dimensional code, location services to achieve the online and offline mobile learning exchange system, and a model that dialogue is services, dialogue is search, and communication is instant to improve the relevance of content, the timeliness of exchange, timeliness of information and the spatiality of location. Learners can read and learn content offered by educational institutions through the mobile device installed with WeChat, and interact anytime, anywhere, which greatly enhances the convenience and efficiency of learning.

\section{Any Learner Can Become Socialized and Provide Resources For the Entire Smart Learning Community.}

Learners can establish connections with other learners and learning resources through WeChat, make analysis and evaluation of learning resources according to their learning needs, and build suitable needs, interests and style of learning environment. There is no fixed learning space, learning partners, learning objectives, learning paths in the smart learning based on WeChat. It has a very significant openness.

\section{STRUCTURING SUPPORT MODEL BASED ON WECHAT SMART LEARNING}

With the emerging of web2.0, social networking sites are more popular and all global are entering an era of Social Network Software at the same time.

For overseas studies, Goldberg put forward a collaborative filtering recommendation system, Tapestry, in 1992. The system are designed to filter E-mails and recommend on-line news based on Query Language, TQL that can reflect users' interest. In china, two studies both show good prospect of Social Network-based knowledge recommendation system. One is the research on former $\mathrm{K}$ Sorting studies recommendation algorithm from XueQi Cheng, who works in computer institution, Chinese Academy of Sciences. The other research is on the recommendation of academic-social networks form Jie Tang, who works in Tsinghua university. Considering functions, features and support function analysis on smart learning of WeChat, it can provide voice-text interaction and group chat model for smart learning, offering a variety of maps, text, sound, image, and other learning resources. At the same time, functions of WeChat, such as public platform-based information polymerization and push, can achieve resources collection features according to the needs of learners, mixing the function of subscribing and pushing to the course content and the function of auto-reply into one, providing smart learning with releasing and retrieval for learning context. What is more, it can offer content analysis to learners' other smart learning, facilitating learners to share resources in different smart learning platforms, providing a variety of services to promote the study of development and learning ${ }^{[11]}$. Under the support of WeChat platform and combining kinds of learning theories, knowledge management and construction theory and so on, the authors try 
to construct a model that WeChat support smart learning, as Fig. 1 shows.

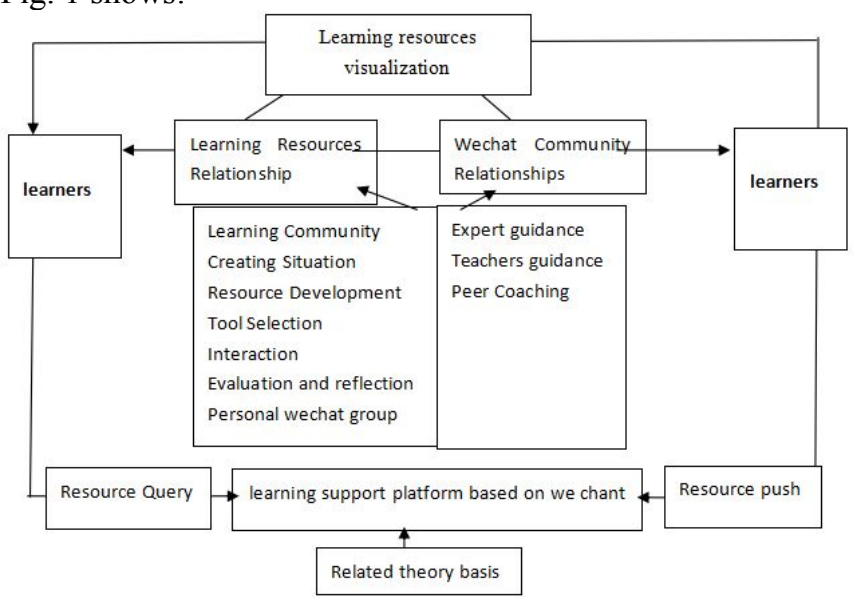

Fig. 1. Structuring Support Model based on WeChat Smart Learning

The framework mainly include four functional modules as follows:

\section{A. SOA Knowledge-based reconstruction according to demand}

WeChat-based learning platform is a SOA-based construction platform firstly. Learning resources are the smallest functional unit of the platform in learners' views. On this basis, build the learner's WeChat network group, in which learners can share and recommend interested education resources with each other in the same WeChat group or in different groups in order to make the full use of learning resources. This can better support seamless learning environment based on ubiquitous learning, free inquiry, knowledge construction and collaborative exchange.

\section{B. Network learning resources matching push based on WeChat}

Push personalized and diverse learning resources to learners. Divide students according to gender or area, then push the specific learning resources to those grouped learners. Analyze their learning situation by their feedback effects (such as collect learners' test grades and questions regularly) after communication and study together, then divide learners again according to individual learning levels. With the help of public service platform, WeChat push studies resources that match their knowledge level to the network circle of friends.

\section{Learner Relationship Modeling Based on WeChat}

Divide learners based on learner behavior, learning motivation and gather learners that have the same or similar learning interest, cognitive style and cognitive abilities. Firstly, deal with the learners' information, data and other information, then divide users' network into several WeChat groups by Community Discovery Algorithm to get users' category of different hobbies. So users in the same WeChat group have the same or similar learning interests, hobbies, cognitive style and cognitive abilities.

\section{Active Visualization Resources Push Based on Learners}

This model is a kind of active resource visualization push. From learners' perspective, learning platform pushes related learning resources (image, text, sound and video) actively to learners according to their WeChat relationship group. From the perspective of knowledge publishing, every learner is also the recommender and publisher of learning materials. They can actively participate in knowledge recommendation and publish (such as the normal learning comments, resource sharing and so on) or passively (for example, the system can find good friends' potential learning interests actively in WeChat group relationship).

\section{IDENTITY PATH ANALYSIS OF SMART LEARNING BASED ON WECHAT PLATFORM}

\section{A. Identity of Smart Learning Environment}

In the smart learning process, how to effectively maintain and promote learner interest is the key to smart learning. Building smart learning environment is not only an important prerequisite to ensure the learners' interest in study, but also a dominant identity factor of the wisdom learners in the smart learning environment. Through the $\mathrm{WeChat}$ group, we can effectively achieve smart learner-centered collaboration, investigative and social blended learning environment, and smart learners have a strong initiative to control and manage personal learning in the learning process. Fig. 2 is the personal wisdom learning environment based on WeChat platform.

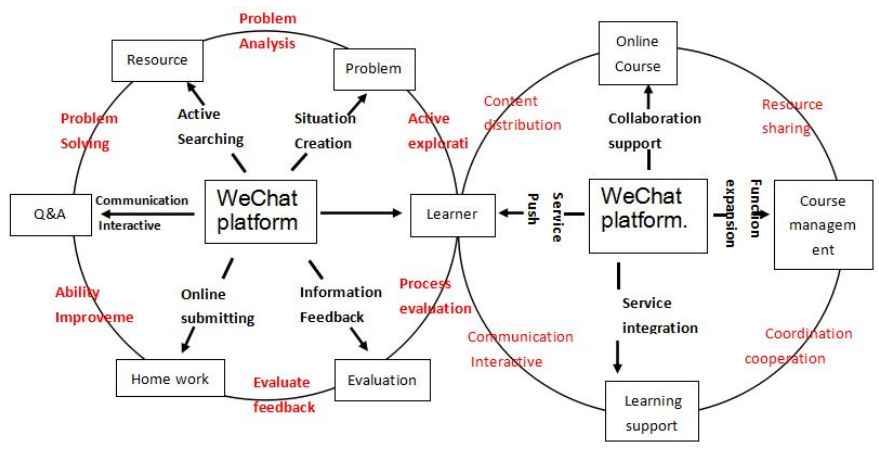

Fig. 2. Learners' individual learning environment based on WeChat

$$
\text { platform }
$$

1) The smart learning "closed-loop" environment. Based on WeChat learning environment, learners can learn about a theme. In the problem situation created based on the WeChat platform for learners to study, learners can use the smart phone and actively search for and use resources during the learning process. At the same time, they can use the WeChat platform's function of information pushing, theme concerning and other functions to utilize the learning resources. We can use voice communication to discuss and answer question by the group of friends. Using the WeChat platform for online questionnaires and homework, and by teachers-students and students-students evaluation including feedback to the learner, a relatively closed learning environment forms. Learners have access to external learning support through WeChat platform for external communication with their circle of friends. In the current Web2.0 and mobile Internet network environment, 
learning resources provided by WeChat platform have the characteristics of being theme-based fragmented. The operation of the system is easy, the effectiveness of interpersonal teaching is high, the pushed learning content is rich and accurate. Meanwhile Wechat platform also aggregates other important characteristics of instant messaging tools such as QQ. All those facilitate the creation of problem situations for wisdom learners, and achieve online learning, $\mathrm{Q}$ $\& \mathrm{~A}$, vote evaluation and homework submission in the smart learning process, and thus a complete "closed loop" learning process forms.

2) With the continuous development of information technology, such series of software like WeChat and QQ, work together to build a social mobile cooperative learning environment, promoting massive open online courses (MOOC) to develop rapidly. MOOC environment and learning content design are also getting increasingly sophisticated, and online courses are becoming a part of smart learning environment based on the WeChat, providing a certain amount of learning support services, for example Coursera, Udacity, edX and Netease cloud classroom. There are some other online classrooms providing fragmented, single theme-based learning resources and learning style for smart learning.

3) In the personal learning environment, through the use of various types of support tools for the learning services, such as cloud storage, calendar management and knowledge management tools, it is primary to help smart learners create a real smart learning situation, provide support for creating a learning experience of exploration, social communication, and interactive learning environment and learning activities ${ }^{[12]}$.

\section{B. The Identity Of the Subjects Of the Study}

Interpersonal communication and cooperation based on WeChat platform for the learning process is usually based on individual fields, but most of this interaction information is based on a colloquial state that learner can accept. In the learning circle, the learner communicate with each other with real names or anonymously. Their sense of belonging and identity of intelligence learning are intense, and they have a certain sense of security, so that the network interaction transferred colloquial voice into the intelligence learning space of WeChat, creating a reliable communication space for the exchange of information between intelligence learners with expressed views and emotional communication. Whether in personal communication or in our circle of friends, learners can demonstrate self-image in the interaction, establish the coordination relationships and achieve good communication and intercourse.

Learners identity recognition is not only incarnated in the transmission of mobile learning information space in WeChat, but also reflected in the transmission of information. Learners identity recognition of smart learning through the microchannel is due to the efficiency and convenience of learning resources that micro-channel and mobile communications bring to the learner. By means of a mobile tool which brings convenience and high mobility, it can achieve learning resources automatic subscription and push, providing fragmented resources and bringing relative consistency of learning to the user through a closed-loop learning circle micro-channel groups, a variety of interactive modes and new learning experience to smart learners.

Identity constructivist learning theory for smart learning object argues that the learning process is the main process that learners construct the knowledge actively. As for smart learner recognition, in order to talk about the construction process of knowledge, the learners use learning resources (smart learning object) and communicate actively through WeChat platform. Learning wisdom through informal learning, we cannot depend on a continued strong presence of the learner's own motivation, we need to stimulate learner motivation effectively. To effectively promote the learning of wisdom, intelligent learning resources must be able to inspire the smart learners' random participation, change the learners on the brink of investment and discontinuous noticing state, adopt the way which is to optimize the experience of the learners as the Fig. 3 shows.

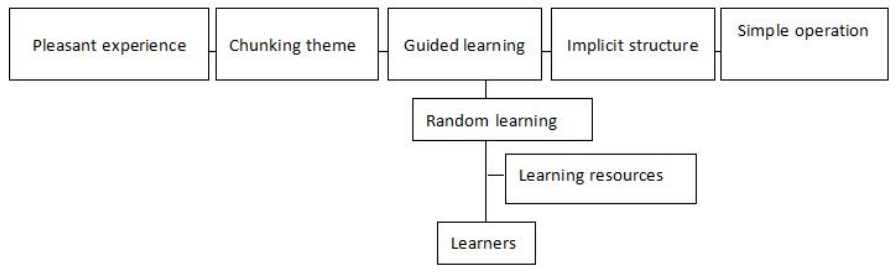

Fig. 3. learning resources for learners support

\section{1) Random participation in learning}

As an informal way of learning, smart learning cannot rely on the learner's own strong motivation to learn, but the learners marginal investment and non-continuity of learning state. In terms of designing learning resources, we should consider their access to or control over learner motivation, always stimulate learner motivation, give learners continuous stimulation and feedback, and guide learners to participate in learning randomly.

\section{2) Group blocking and dominance of the learning resources}

An important feature of smart learning resources is miniaturization. WeChat platform-based learning emphasizes the differentiation of learning content chunk style and nuances of learning content. According to the characteristics of smart learning, differentiated content resources should be a theme or a complete knowledge of the block, and learners can learn in a short time conveniently.

\section{3) Implicit knowledge structure}

In the WeChat platform learning, fragmentation of learning resources need to establish implicit knowledge structure for different segments of the learning resources, but how to combine the fragmented independent learning resources together and then form an implicit knowledge structure should take consideration of the principled combining push mode that resources designers adopt with learning paths.

\section{4) Convenient operation}

Smart learning process is a mobile activity flow which consists of a series of smart learning micro-stimulation and micro reaction. How to effectively maintain the learning 
interest of the learner? It requires the smart learners to be able to interact with the learning terminal or learning system, the technical difficulty of this kind of interaction is the key problem to be solved in the design of WeChat platform, Learning resources should be as far as possible to make intuitive, simple and convenient to achieve a continuous interaction between the learning interface and learners. ${ }^{[13]}$

\section{5) Pleasant experience}

WeChat learning should give learners free and happy learning experience. In the learning design process, the designer should consider the intelligent learners' free and open learning attitude, flexible attention, free access of learning resources and automatic participation in the learning process of interaction.

Because of the differences between learners, in the design of their learning patterns and resources, they need to take into account the learning characteristics of learners, make the course content clear and learning resources modulized, make the operation simple, emphasize random participation and active interaction design principles. The designer should take the learning experience of the learner as the primary function of the learning design. How to play and explore the function of the WeChat to build a new type of intelligent learning environment? How to stimulate the learning interest of the learner? How to create a new optimized model and identity path of intelligent learning? These questions are the focuses of research and discussion.

\section{CONCLUSION}

With the continuous growth of WeChat users and the series of changes brought by new technologies, such as learning style, learning environment, etc, WeChat is the basic condition from a technical point of view to satisfy the learners to carry out personalized, differentiated, and other smart learning. Smart learning environments based on WeChat platform have wider entrance, being more interactive, entertaining and convenient. At the same time, it can make learning and interactive platform extend from virtual to reality, then use virtual interaction to promote real interaction through combining online and offline with each other, which can not only exert face-to-face communication efficiency in traditional teaching, but also experience the convenience of interaction of virtual community. It not only fully mobilizes the initiative of learners and meet the needs of social learning and life-long learning society, but also provide new ideas and ways to promote the process of education informatization and personalized, differentiated education.

\section{References}

[1] F.L. Meng and L. Chen, "Research on the construction of mobile learning space based on WeChat public platform," Modern educational technology, vol. 10, pp. 19-25, 2014.

[2] Office of Educational Technology, U.S, Department of Education. Transforming American Education: Learning Powered by Technology, U.S.2010.

[3] L. Yuan, X.H. Chen and Y.L. Zhang, "Hybrid learning research based on WeChat support- Take "the basic technology of photography" as an example," China Educational Technology, vol.7, pp. 128-132,2012.

[4] H. Bai, "Research on the application of WeChat public platform in the field of Higher Education," China Education Informationization, vol. 4, pp. 78-81, 2013

[5] P. Wang, "Analysis of support functions and design principles of WeChat mobile learning," Distance Education Journal, vol. 6, pp. 34-41, 2013.

[6] Y. Luo, "WeChat learning, Get back the time of the fingers," Distance Education in China(Information)vol. 12, pp. 99-100, 2013.

[7] Z.T. Zhu and B. He, "Smart Education: The New Realm Of Educational Informationization," E-education Research, vol. 12, pp. 5-13, 2012.

[8] M.S. Le and Y.E. Son, "A Study on the Adoption of SNS for Smart Learning in the"Creative Activity"," International Journal of Education and Learning, vol. 3, pp. 1-18, 2012 .

[9] Z.T. Zhu and B. He, "Smart Education: The New Realm Of Educational Informationization," E-education Research, vol. 12, pp. 5-13, 2012.

[10] B. He, "Smart Learning: Connotation ,evolution and trend-- The learner's perspective,” E-education Research, vol.11, pp. 24-33,2013.

[11] Y. Yuan and C.M. Yang, "Empirical research on the social networks and their relationship in the process of information exchange of micro blog users," Library and Information Service, vol. 55, pp. 31-35, June,2011.

[12] Y.T. Liu, "Research on the application of WeChatl public learning platform in mobile learning," Software guide - Educational technology, vol. 10, pp. 91-93, 2013.

[13] E. Bray and F. Khaddage. "Mobile computing and Educational Innovation In Japan," In R. Mcbridc and M. Scarson(Eds), procceedings of Society for Information Technoloiry \& Teacher Education International Conference,chesapeake, VA:AACE, 2013. 